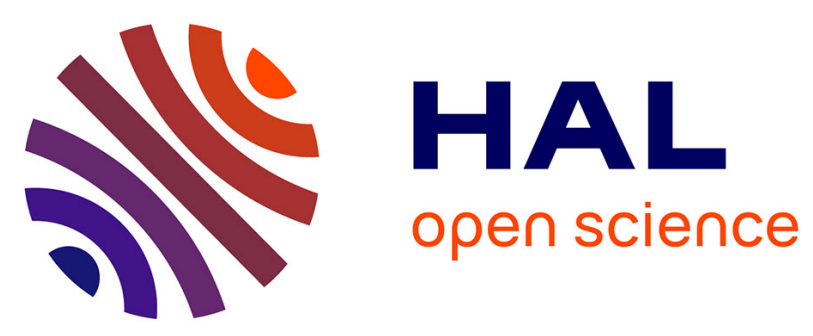

\title{
Dyspnea: An underestimated symptom in Parkinson's disease
}

Guillaume Baille, Cécile Chenivesse, Thierry Perez, François Machuron, Kathy Dujardin, David Devos, Luc Defebvre, Caroline Moreau

\section{- To cite this version:}

Guillaume Baille, Cécile Chenivesse, Thierry Perez, François Machuron, Kathy Dujardin, et al.. Dyspnea: An underestimated symptom in Parkinson's disease. Parkinsonism \& Related Disorders, 2019, 60, pp.162 - 166. 10.1016/j.parkreldis.2018.09.001 . hal-03485915

\section{HAL Id: hal-03485915 https://hal.science/hal-03485915}

Submitted on 20 Dec 2021

HAL is a multi-disciplinary open access archive for the deposit and dissemination of scientific research documents, whether they are published or not. The documents may come from teaching and research institutions in France or abroad, or from public or private research centers.
L'archive ouverte pluridisciplinaire HAL, est destinée au dépôt et à la diffusion de documents scientifiques de niveau recherche, publiés ou non, émanant des établissements d'enseignement et de recherche français ou étrangers, des laboratoires publics ou privés.

\section{(ㄷ)(1) $\$$}

Distributed under a Creative Commons Attribution - NonCommerciall 4.0 International 


\section{Dyspnea: an underestimated symptom in Parkinson's disease.}

Guillaume Baille ${ }^{1}$, Cécile Chenivesse ${ }^{2}$, Thierry Perez ${ }^{2}$, François Machuron ${ }^{3}$, Kathy Dujardin', David Devos ${ }^{1}$, Luc Defebvre ${ }^{1}$, Caroline Moreau ${ }^{1}$

1. Department of Neurology, Expert Center for Parkinson's Disease, INSERM UMRS_1171, Lille University Medical Center, LICEND COEN center, Lille, F-59000 France

2. CHU Lille, Service de Pneumologie et Immuno-Allergologie, Centre de Compétence pour les Maladies Pulmonaires Rares, Univ. Lille, , INSERM U1019, CIIL, Institut Pasteur de Lille, F-59000 Lille, France

3. Univ. Lille, CHU Lille, EA 2694 - Santé Publique: Épidémiologie et Qualité des Soins, Department of Biostatistics, F-59000 Lille, France

Number of words: $2388 / 3000$

Number of references: $30 / 30$

\section{Figure 3/4}

Corresponding author: Guillaume Baille, MD, quillaume.baille@chru-lille.fr, +33320445962

Department of Neurology and Movement Disorders, Lille University Medical Center, Lille, France 
Abstract (201/250)

Introduction: Dyspnea is one of the least well-characterized non-motor symptoms (NMS) associated with Parkinson's disease (PD).

Objective: To determine the frequency of dyspnea in a large, single-center cohort of consecutive PD patients with no history of lung or heart disease, and to compare clinical features in dyspneic vs. non-dyspneic patients.

Methods: Patients with abnormal cardiovascular and pulmonary results in a clinical examination were excluded. A positive response to at least one question ("In the last month, have you suffered from breathlessness?" and "In the last month, have you had trouble breathing normally?") was considered to signify the experience of dyspnea. MDS-UPDRS, global cognitive performance, non-motor symptoms and quality of life were assessed.

Results: In the cohort of 153 non-demented PD patients (mean age \pm standard deviation: $63.9 \pm 7.4$; mean disease duration: $9.2 \pm 6.1$ years), the mean [95\% confidence interval $(\mathrm{Cl})$ ] frequency of dyspnea was $39.2 \%$ (31.5-47). After adjustment for disease severity, PD patients with dyspnea had a significantly higher Movement Disorders Society Unified Parkinson's Disease Rating Scale part I, II and IV scores, a higher HAD anxiety and depression scores and a significantly higher 8-item Parkinson's Disease Questionnaire.

Conclusion: Dyspnea is a frequent NMS in PD. Its pathophysiology and prognostic value need more investigation. 
Introduction

Dyspnea is one of the least well-characterized non-motor symptoms (NMSs) associated with Parkinson's disease (PD). Dyspnea has been defined by the American Thoracic Society as "a subjective experience of breathing discomfort that consists of qualitatively distinct sensations that vary in intensity... [it] derives from interactions among multiple physiological, psychological, social, and environmental factors, and may induce secondary physiological and behavioral responses [1]." Dyspnea is a common symptom of respiratory, cardiac, neuromuscular, and psychological disorders. In an observational study of patients attending a movement disorders department, most cases of dyspnea were associated with heart and lung diseases [2]. However, many clinicians are unaware that dyspnea is also listed as a NMS of PD [3].

In neurodegenerative diseases such as amyotrophic lateral sclerosis, the associated neuromuscular impairment of respiratory muscles means that dyspnea is a frequent symptom. In PD, the precise mechanisms involved in dyspnea remain unknown [4]. Furthermore, the literature data on the frequency of dyspnea in PD are contradictory: a prevalence of $40 \%$ was reported in a cohort of 50 fluctuating PD patients [5], whereas the PRIAMO study of 1072 patients found a value of only $11.5 \%$ [6]). Since dyspnea is a marker for poor quality of life and is associated with a loss of autonomy in ambulatory elderly patients [7], a specific study of dyspnea in PD is lacking, even more in patients without fluctuations.

The diagnosis of dyspnea can still be challenging; the multidimensional, subjective aspect of this diagnosis might account for the wide range of prevalence values reported to date. It is a self-reported symptom and must not be mistaken with tachypnea or intercostal indrawing. Therefore, without an active approach, physicians can miss the existence of the dyspnea. Furthermore, dyspnea is the only NMS included in two different categories (dysautonomia and sensorial) in the classification developed by Susan \& Lang [3].

The primary objective of the present study was to determine the prevalence and clinical characteristics of dyspnea in a large cohort of PD patients. The secondary objective was to compare the clinical features between dyspneic and non dyspneic PD patients.

\section{Methods}

In a prospective single-center study, consecutive PD patients were asked whether they experienced dyspnea. The main inclusion criteria were physician-diagnosed PD (according to the Movement Disorders Society Clinical Diagnostic Criteria for PD (2015)) and age between 18 and 85. We excluded patients with (i) atypical parkinsonism, (ii) cognitive impairment (as evidenced by a Montreal Cognitive Assessment (MoCA [8]) score $\leq 24$ out of 30), (iii) a pulmonary, cardiac or ENT pathology that may lead to dyspnea, (iv) intercurrent ENT, cardiac or ENT infection in the last month and (v) abnormal cardiac and/or pulmonary results in a clinical examination. The procedures were approved by an ethical standards committee.

All the clinical examinations were performed by a neurologist expert in movement disorders, and included the Movement Disorders Society Unified-Parkinson's Disease Rating Scale (MDS-UPDRS [9]), the Hoehn and Yahr score (H\&Y [10]). NMSs were screened with the Non-Motor Symptoms Questionnaire (NMS Quest [11]), the anxiety and depression by the Hospital Anxiety and Depression scale (HAD [12]), and quality of life was assessed using the 8-item Parkinson's Disease Questionnaire (PDQ8 [13]). Patients were classified in three motor phenotypes, according to the clustering proposed by Eisinger et al. 2017 (Tremor-Dominant, Postural Instability and Gait Disorder and Akinetic-Dominant corresponding to Intermediate Type [14]).

Dyspnea is mostly reported by patients as "breathlessness" and "inability to breathe deeply" [15]. Therefore, in order to determine the prevalence of dyspnea in our study population, patients were asked the following two 
questions (used routinely in pulmonology): "In the last month, have you experienced breathlessness or have you had trouble breathing normally?" Dyspnea was diagnosed if the answer to at least one question was "yes". Respiratory disability was assessed using the mMRC scale (from 0 (no disability) to 4 (complete disability): zero for dyspnea only with strenuous exercise; 1 for dyspnea when hurrying or walking up a slight hill; 2 if the patient walks slower than people of the same age because of dyspnea or has to stop for breath when walking at own; 3 if the patient stops for breath after walking 100 yards $(91 \mathrm{~m})$ or after a few minutes; 4 if the patient is too dyspneic to leave house or breathless when dressing [16]. Patients were also asked to determine if the symptom was associated with motor fluctuations.

Quantitative variables were described as the mean \pm standard deviation (SD) or the median [interquartile range $(I Q R)]$ in case of non-normal distribution. The normality of distribution was checked graphically and using the Shapiro-Wilk test. Categorical variables were described as the frequency (percentage). Patient's clinical features were compared between the two study groups (patients with vs. with no dyspnea) using Student's tests (or Mann-Whitney $U$ tests for non-normal distributions) for continuous variables and using Chi-Squared tests (or Fisher's exact test when expected cell frequency was $<5$ ) for categorical variables. Between-group comparisons were further adjusted for disease motor severity (H\&Y and MDS-UPDRS III) using logistic regression models, with the presence of dyspnea and the mMRC score as the dependent variable. The prevalence of dyspnea was also compared as a function of the H\&Y grade using a Cochran-Armitage trend test. The threshold for statistical significance was set to $p<0.05$. All analyses were performed using SAS software (version 9.4, SAS Institute, Cary, NC, USA).

\section{Results}

A total of 248 consecutive PD patients with a MoCA score $>24$ out of 30 were pre-selected (flow-chart in supplementary data). Firstly, sixty of them were excluded due to disease associated with dyspnea: 37 with pulmonary disease ( 23 with chronic obstructive pulmonary disease, 8 with asthma, 4 with lung cancer, 1 with pleurisis and 1 with pneumothorax), 29 with cardiac disease (13 arrhythmia, 11 ischaemic cardiopathy, 5 valvular heart disease) and 8 with ENT disease (5 chronic rhinitis, 2 cancers, 2 local post-surgery complications). Secondly, 8 patients were excluded because of intercurrent ENT or pulmonary infection in the last month (5 with rhinitis and 3 with pneumonia). Lastly, abnormal cardiac and/or pulmonary examination was found in 27 patients (12 with irregular heartbeats, 9 with heart murmurs, 6 with sibilances).Therefore, 153 PD patients (mean age of $63.9 \pm 7.4$ years old; M/F: $90 / 63 ; 4.0 \%$ of current smoker and mean disease duration of $9.2 \pm 6.1$ years) were included (clinical features of the cohort in table 1).

Dyspnea was observed in 60 of the 153 PD patients, which corresponds to a frequency [ $95 \% \mathrm{Cl}$ ] of 39.2 [31.547.0]\%). Adjusted for disease motor severity (H\&Y and MDS-UPDRS III), compared with non-dyspneic PD patients, dyspneic PD patients had higher MDS-UPDRS part I $(p<0.001)$, II $(p<0.001)$, and IV $(p=0.004)$ scores, a higher HAD anxiety and depression scores (respectively $p<0.001$ and $p=0.0005$ ) and a higher PDQ8 score $(p<0.001$ ) (Table 2). The more severe the PD, the more prevalent the dyspnea: $13.8 \%$ for H\&Y [1.5-2] vs. $71.2 \%$ for H\&Y [2.5-3]; $p<0.001$; (Figure 1A). Yet, the severity of the mMRC scale was neither associated with $\mathrm{H} \& Y$ $(p=0.12)$ nor with $\mathrm{HAD}$ anxiety and depression scores (respectively $p=0.2$ and $p=0.38$ ).

Regarding the association with other NMSs, dyspnea was significantly correlated with all the sub-items of the MDS-UPDRS I score (figure 1B), except for features of dopaminergic dysregulation $(\mathrm{OR}[95 \% \mathrm{Cl}]$ : 1.49 ; [0.88;2.51]). The severity of axial symptoms of PD (dysphagia in MDS-UPDRS II score, gait and speech in MDSUPDRS III score) was also associated with dyspnea (figure 1B). 
In the group of patients who reported dyspnea in the last month ( $n=60)$, the duration of dyspnea was $4.6 \pm 2.4$ years, with much more occurrence of the symptom during wearing-off times $(48.3 \%)$ than during disphasic and peak-dose dyskinesia (6.7\%). Yet, $45 \%$ of the dyspneic patients were not able to link the shortness of breath and the motor fluctuations. The mean degree of dyspnea was $1.3 \pm 0.8$.

\section{Discussion}

To our knowledge, the present study is the first to have specifically assessed the prevalence of dyspnea in a large, prospective cohort of PD patients. Dyspnea was found to be a frequent symptom (affecting almost $40 \%$ of the patients), and was correlated with motor disease severity. Additionally, dyspneic patients suffered from more severe motor fluctuations and axial symptoms.

In the PRIAMO study, only $11.5 \%$ of the patients experienced dyspnea [6]. However, our cohort included participants with a longer disease duration (9.2 years vs. 5.1 years) and dyspnea might be associated with disease severity (Hoehn and Yahr stage). Furthermore, our questions were designed to be more sensitive than the structured interview used to assess NMS [17]. This study could have been less sensitive than ours as the authors only assessed dyspnea on exertion by using a standard palliative care assessment tool. Our results are similar to those reported in a British cohort (shortness of breath on exertion was reported by $35.8 \%$ among 123 PD patients) [18]. Even if Witjas et al. observed $40 \%$ of dyspneic PD patients, it can hardly been compared with our cohort as they included only fluctuating PD patients and they did not exclude those with potential causes of dyspnea [5]. Unlike their study in which 54 NMS were assessed, we mainly focused on shortness of breath. Therefore, our patients may have paid more attention to this specific symptom and may have reported it more frequently.

Unfortunately, we could not compare the prevalence of dyspnea with an age-matched population, but our prevalence of $39 \%$ is higher than the self-reported value of $25 \%$ of dyspneic patients in the PAQUID cohort (in which 3,777 individuals aged 65 years or older were monitored in order to determine the effects of environmental, behavioral, and social vectors of age-related medical conditions and diseases [19]). Dyspnea seems much more frequent in elderly people than in general population [20;21]. Huijnen et al. highlighted $23 \%$ of patients older than 70 years old with dyspnea, but they did not exclude those with cardio-pulmonary comorbidities [21]. The mean age in our cohort was lower $(63.9 \pm 7.4$ years old $)$ and the age was not significantly different between the patients with or without dyspnea $(p=0.2)$ One can thus legitimately expect PD to have a role in the occurrence of dyspnea. However, in our cohort, even if no patients had a known cardiac, pulmonary or ENT disease and/or an abnormal auscultation, it seems important to address the dyspneic PD patients to a specialist in order to be sure that the symptom is only the consequence of the neurodegenerative disease. Participants reporting dyspnea were addressed to their general practitioner for further investigations.

Although Susan \& Lang did not classify dyspnea as a neuropsychiatric NMS [3], its link with anxiety has already been displayed [22;23]. In our cohort, dyspneic patients were significantly more anxious and depressed. In a cross-sectional study, $34 \%$ of PD subjects met the DSM IV criteria for at least one anxiety disorder and $50 \%$ had clinically relevant symptoms of anxiety [24]. However, the HAD scale has no items for the assessment of somatic manifestations of anxiety. Therefore, for now, we cannot attribute the difference observed in our cohort to the overlap between respiratory symptoms and anxiety. Additionally, respiratory symptoms in patients with asthma (including breathlessness) were more common in those with anxiety or depression [25]. More specific tools could be used to evaluate anxiety and depression in PD in order to point out the impact of these neuropsychiatric symptoms in dyspnea. Nevertheless, in PD, dyspnea is likely to be multifactorial [4]. Indeed, it could be a sign of an objective respiratory disturbance in PD. As dyspnea is the main symptom of respiratory disturbance and PD can affect the ventilatory function [4], the close association of dyspnea with the severity of dysphagia, dysarthria 
raises the question of shortness of breath as a warning sign of upper-body axial manifestations of the disease. Yet, in the present study, the patients with dyspnea were not more likely to require physical rehabilitation and speech therapy (Table 2). Furthermore, Barone et al. found that respiratory symptoms were the fifth most impactful symptoms with regard to the quality of life [6]; indeed, we found that dyspneic patients had a higher PDQ8 score.

Our study suffered from some limitations. Firstly, our cohort was recruited from a single center (a tertiary hospital). However, the mean age, disease duration and NMS scores in our study were similar to those published for other cohorts [26;27]. Secondly, we cannot rule out self-reporting bias among the patients. Some patients might have not perceived their dyspnea because of a disease-related physical limitation or might even have mistaken it for a motor impairment. However, these points could have led us to underestimate (and not overestimate) the prevalence of dyspnea. Furthermore, the diagnosis of dyspnea was based on a question used in routine clinical care by pulmonologists specializing in dyspnea. As dyspnea is a subjective perception of breathing discomfort [28], the assignment of a patient to the symptomatic group depended on his personal experience spontaneously reported. Indeed, there is no threshold or no validated questionnaire to consider if someone is dyspneic or not dyspneic. The open-ended question used to screen dyspnea is the main strength of our study because we did not restrict it to respiratory disability. mMRC scale assesses the functional impairment due to dyspnea [15]. Therefore, it does not seem to be adequate in Parkinson, since akinesia, hypertonia or gait can hinder the patient's mobility. New questionnaires like the Multidimensional dyspnea profile (MDP [29]) could help to improve the screening. Thirdly, as the existence of a potential cardiac, pulmonary or ENT cause of dyspnea was an exclusion criterion, we did not assess the prevalence of dyspnea in these patients. Moreover, as the exclusion criteria depended on the patient's past history and on clinical examination, in some participants, dyspnea could be due to undiagnosed cardiac or lung disease. Lastly, the lack of lung function testing in our patients is the last limitation. These data would help to indicate whether dyspnea is associated with an objective change in lung volumes or flows, respiratory muscle strength or even the response to hypoxemia. Likewise, lung function testing might help to understand better the pathophysiological mechanisms underlying dyspnea in PD [30].

\section{Conclusion}

Dyspnea is a frequent symptom in PD, and is related to the disease severity, motor fluctuations, anxiety and depression. Further research is needed to understand the pathophysiology of dyspnea in PD and the impairment's prognostic value. A better understanding of the underlying mechanisms could help to propose a specific management of this symptom in PD patients.

1. Parshall MB, Schwartzstein RM, Adams L, Banzett RB, Manning HL, Bourbeau J, Calverley PM, Gift AG, Harver A, Lareau SC, Mahler DA, Meek PM, O'Donnell DE; American Thoracic Society Committee on Dyspnea. An official American Thoracic Society statement: update on the mechanisms, assessment, and management of dyspnea. Am J Respir Crit Care Med. 2012;185(4):435-52.

2. Yust-Katz S, Shitrit D, Melamed E, Djaldetti R. Respiratory distress: an unrecognized non-motor phenomenon in patients with parkinsonism. J Neural Transm (Vienna). 2012;119(1):73-6.

3. Susan HF, \& Lang AE Motor and nonmotor fluctuations. Handbook of Clinical Neurology. Elsevier 2007, Edinburgh-Toronto, pp. 159-184.

4. Baille G, De Jesus AM, Perez T, Devos D, Dujardin K, Charley CM, Defebvre L, Moreau C. Ventilatory Dysfunction in Parkinson's Disease. J Parkinsons Dis. 2016 Jun 16;6(3):463-71. 
5. Witjas T, Kaphan E, Azulay JP, Blin O, Ceccaldi M, Pouget J, Poncet M, Chérif AA. Nonmotor fluctuations in Parkinson's disease: frequent and disabling. Neurology. 2002;59(3):408-13.

6. Barone P, Antonini A, Colosimo C, Marconi R, Morgante L, Avarello TP, Bottacchi E, Cannas A, Ceravolo G, Ceravolo R, Cicarelli G, Gaglio RM, Giglia RM, lemolo F, Manfredi M, Meco G, Nicoletti A, Pederzoli M, Petrone A, Pisani A, Pontieri FE, Quatrale R, Ramat S, Scala R, Volpe G, Zappulla S, Bentivoglio AR, Stocchi F, Trianni G, Dotto PD; PRIAMO study group. The PRIAMO study: A multicenter assessment of nonmotor symptoms and their impact on quality of life in Parkinson's disease. Mov Disord. 2009;24(11):1641-9.

7. Ho SF, O'Mahony MS, Steward JA, Breay P, Buchalter M,\& Burr ML (2001) Dyspnoea and quality of life in olderpeople at home. Age Ageing, 2, 155-159.

8. Nasreddine ZS, Phillips NA, Bédirian V, et al. The Montreal Cognitive Assessment, MoCA: a brief screening tool for mild cognitive impairment. J Am Geriatr Soc. 2005;53(4):695-9.

9. Goetz CG1, Tilley BC, Shaftman SR, Stebbins GT, Fahn S, Martinez-Martin P, Poewe W, Sampaio C, Stern MB, Dodel R, Dubois B, Holloway R, Jankovic J, Kulisevsky J, Lang AE, Lees A, Leurgans S, LeWitt PA, Nyenhuis D, Olanow CW, Rascol O, Schrag A, Teresi JA, van Hilten JJ, LaPelle N; Movement Disorder Society UPDRS Revision Task Force. Movement Disorder Society-sponsored revision of the Unified Parkinson's Disease Rating Scale (MDS-UPDRS): scale presentation and clinimetric testing results. Mov Disord. 2008;23(15):212970.

10. Hoehn MM, Yahr MD. Parkinsonism: onset, progression and mortality. Neurology. 1967;17(5):427-42.

11. Chaudhuri KR, Martinez-Martin P, Schapira AH, Stocchi F, Sethi K, Odin P, Brown RG, Koller W, Barone P, MacPhee G, Kelly L, Rabey M, MacMahon D, Thomas S, Ondo W, Rye D, Forbes A, Tluk S, Dhawan V, Bowron A, Williams AJ, Olanow CW: International multicenter pilot study of the first comprehensive selfcompleted nonmotor symptoms questionnaire for Parkinson's disease: the NMSQuest study. Mov Disord 2006;21:916-923.

12. Zigmond A.S., Snaith R.P. The Hospital Anxiety and Depression Scale. Acta Psychiatr. Scand., 1983, 67, 361-370.

13. Jenkinson C, Fitzpatrick R, Peto V. The Parkinson's disease questionnaire; User manual for the PDQ39, PDQ-8 and PDQ summary index. Oxford: Health Services Research Unit, Department of Public Health, University of Oxford; 1998.

14. Eisinger RS, Hess CW, Martinez-Ramirez D, Almeida L, Foote KD, Okun MS, Gunduz A. Motor subtype changes in early Parkinson's disease. Parkinsonism Relat Disord. 2017;43:67-72.

15. Brenner S, Güder G. The patient with dyspnea. Rational diagnostic evaluation. Herz. 2014;39(1):8-14.

16. Bestall JC, Paul EA, Garrod R, Garnham R, Jones PW, Wedzicha JA. Usefulness of the Medical Research Council (MRC) dyspnoea scale as a measure of disability in patients with chronic obstructive pulmonary disease. Thorax. 1999; 54(7):581-6.

17. Antonini A, Colosimo C, Marconi R, Morgante L, Barone P; PRIAMO study group. The PRIAMO study: background, methods and recruitment. Neurol Sci. 2008;29(2):61-5.

18. Lee MA, Prentice WM, Hildreth AJ, Walker RW. Measuring symptom load in Idiopathic Parkinson's disease. Parkinsonism Relat Disord. 2007;13(5):284-9.

19. Nejjari C, Tessier JF, Baldi I, Barberger-Gateau P, Dartigues JF, Salamon R. Epidemiologic aspects of respiratory aging: contribution of the PAQUID survey. Rev Epidemiol Sante Publique. 1997;45(5):417-28.

20. Figarska SM, Boezen HM, Vonk JM. Dyspnea severity, changes in dyspnea status and mortality in the general population: the Vlagtwedde/Vlaardingen study. Eur J Epidemiol. 2012; 27(11): 867-876.

21. Huijnen $B$, van der Horst $F$, van Amelsvoort $L$, Wesseling $G$, Lansbergen $M$, Aarts $P$, Nicolson $N$, Knottnerus A. Dyspnea in elderly family practice patients. Occurrence, severity, quality of life and mortality over an 8-year period. Fam Pract. 2006;23(1):34-9.

22. Storch A, Schneider CB, Wolz M, Stürwald Y, Nebe A, Odin P, Mahler A, Fuchs G, Jost WH, Chaudhuri KR, Koch R, Reichmann H, \& Ebersbach G (2013) Nonmotor fluctuations in Parkinson disease: Severity and correlation with motor complications. Neurology, 9, 800-809. 
23. Leentjens AFG, Dujardin K, Marsh L, Martinez-Martin P, Richard IH, \& Starkstein SE (2012) Anxiety and motor fluctuations in Parkinson's disease: A cross-sectional observational study. Parkinsonism Relat Disord, 10, 1084-1088.

24. Leentjens AF, Dujardin K, Marsh L, Martinez-Martin P, Richard IH, Starkstein SE. Symptomatology and markers of anxiety disorders in Parkinson's disease: a cross-sectional study. Mov Disord. 2011;26(3):484-92.

25. Leander M, Lampa E, Rask-Andersen A, Franklin K, Gislason T, Oudin A, Svanes C, Torén K, Janson C. Impact of anxiety and depression on respiratory symptoms. Respir Med. 2014;108(11):1594-600.

26. Maeda T, Shimo Y, Chiu SW, Yamaguchi T, Kashihara K, Tsuboi Y, Nomoto M, Hattori N, Watanabe H, Saiki H; J-FIRST group. Clinical manifestations of nonmotor symptoms in 1021 Japanese Parkinson's disease patients from 35 medical centers. Parkinsonism Relat Disord. 2017;38:54-60.

27. Todorova A, Jenner P, Ray Chaudhuri K. Non-motor Parkinson's: integral to motor Parkinson's, yet often neglected. Pract Neurol. 2014;14(5):310-22.

28. Parshall MB, Carle AC, Ice U, Taylor R, Powers J. Validation of a three-factor measurement model of dyspnea in hospitalized adults with heart failure. Heart Lung. 2012;41(1):44-56.

29. Banzett RB, O'Donnell CR, Guilfoyle TE, Parshall MB, Schwartzstein RM, Meek PM, Gracely RH, Lansing RW. Multidimensional Dyspnea Profile: an instrument for clinical and laboratory research. Eur Respir J. 2015;45(6):1681-91.

30. Baille G, Perez T, Devos D, Deken V, Defebvre L, Moreau C. Early occurrence of inspiratory muscle weakness in Parkinson's disease. PLoS One. 2018;13(1):e0190400. 
Table 1: clinical features of the cohort.

\begin{tabular}{|c|c|}
\hline Parameter & All patients $(\mathrm{N}=153)$ \\
\hline Age (Years), Mean \pm SD & $63.9 \pm 7.4$ \\
\hline Sex, M/F & $90 / 63$ \\
\hline \multicolumn{2}{|l|}{ Smoking, N(\%) } \\
\hline Never & $122(79.7)$ \\
\hline Past smoker & $25(16.3)$ \\
\hline Smoker & $6(4.0)$ \\
\hline Disease duration (Years), Median (Q1 ; Q3) & $8.0(3.0 ; 13.0)$ \\
\hline \multicolumn{2}{|l|}{ Motor phenotype, $\mathrm{N}(\%)$} \\
\hline Tremor-dominant & $51(33.3)$ \\
\hline Akinetic-dominant & $83(54.2)$ \\
\hline PIGD & $19(12.5)$ \\
\hline \multicolumn{2}{|l|}{ Dopaminergic continuous stimulation, $\mathrm{N}(\%)$} \\
\hline No & $114(74.6)$ \\
\hline DBS (only STN) & $27(17.6)$ \\
\hline Apomorphine subcutaneous infusion & $8(5.2)$ \\
\hline Duodenal infusion & $4(2.6)$ \\
\hline Levo-DOPA daily dose equivalency (mg), Median (Q1 ; Q3) & $700.0(310.0 ; 1100)$ \\
\hline MDS-UPDRS I, Median (Q1 ; Q3) & $9.0(6.0 ; 14.0)$ \\
\hline MDS-UPDRS II, Median (Q1 ; Q3) & $26.0(17.5 ; 31.0)$ \\
\hline MDS-UPDRS III, Median (Q1 ; Q3) & $33.0(22.0 ; 42.0)$ \\
\hline MDS-UPDRS IV, Median (Q1 ; Q3) & $8.0(6.0 ; 12.0)$ \\
\hline Patients with motor fluctuations, $\mathrm{N}(\%)$ & $100(65.7)$ \\
\hline \multicolumn{2}{|l|}{ Hoen \& Yahr, N(\%) } \\
\hline 1 & $22(14.4)$ \\
\hline 1.5 & $0(0.0)$ \\
\hline 2 & $65(42.5)$ \\
\hline 2.5 & $44(28.8)$ \\
\hline 3 & $15(9.8)$ \\
\hline 4 & $7(4.5)$ \\
\hline PDQ8, Median (Q1 ; Q3) & $9.0(5.0 ; 15.0)$ \\
\hline Physiotherapy, N(\%) & $85(55.6)$ \\
\hline $\begin{array}{l}\text { Frequency of physiotherapy sessions per week, Median (Q1 ; } \\
\text { Q3) }\end{array}$ & $3.0(2.0 ; 3.0)$ \\
\hline Speech therapy, N(\%) & $23(15.0)$ \\
\hline
\end{tabular}

PIGD: postural instability gait difficulty, DBS: deep brain stimulation, STN: sub-thalamic nucleus, MDS-UPDRS: Movement disorders society-Unified Parkinson's disease rating scale, MoCA: Montréal Cognitive Assessment, PDQ: Parkinson's disease questionnaire. 
Table 2: comparisons of patients with and without dyspnea

\begin{tabular}{|c|c|c|c|c|}
\hline & $\begin{array}{l}\text { Patients without } \\
\text { dyspnea } \\
(\mathrm{N}=93)\end{array}$ & $\begin{array}{l}\text { Patients with dyspnea } \\
\qquad(\mathrm{N}=60)\end{array}$ & p & $p$ adjusted $*$ \\
\hline Age (years), mean \pm SD & $63.3 \pm 6.7$ & $64.9 \pm 8.3$ & 0.20 & - \\
\hline Sex, M/F & $59 / 34$ & $31 / 29$ & 0.15 & - \\
\hline \multicolumn{5}{|l|}{ Smoking, n (\%) } \\
\hline Never smokers & $76(81.7)$ & $46(76.7)$ & \multirow{3}{*}{ NA } & \multirow{3}{*}{-} \\
\hline Former smokers & $14(15.1)$ & $11(18.3)$ & & \\
\hline Current smokers & $3(3.2)$ & $3(5.0)$ & & \\
\hline Disease duration (years), median [IQR] & $6.0(3.0 ; 10.0)$ & $12.0(8.0 ; 16.0)$ & $<0.001$ & - \\
\hline \multicolumn{5}{|l|}{ Motor phenotype, n (\%) } \\
\hline Tremor-dominant & 38 (40.9) & $13(21.6)$ & \multirow{3}{*}{$<0.001$} & \multirow{3}{*}{0.98} \\
\hline Akinetic-rigid & $52(55.9)$ & $31(51.7)$ & & \\
\hline $\mathrm{PI} / \mathrm{GD}$ & $3(3.2)$ & $16(26.7)$ & & \\
\hline \multicolumn{5}{|l|}{ Continuous dopaminergic stimulation, $\mathrm{n}(\%)$} \\
\hline No & $75(80.6)$ & $39(65.0)$ & \multirow{4}{*}{ NA } & \multirow{4}{*}{ NA } \\
\hline DBS (STN in all cases) & $15(16.2)$ & $12(20.0)$ & & \\
\hline Apomorphine subcutaneous infusion & $3(3.2)$ & $5(8.3)$ & & \\
\hline Duodenal infusion & $0(0.0)$ & $4(6.7)$ & & \\
\hline Levo-DOPA daily dose equivalency (mg), median [IQR] & $462.0(200.0 ; 840.0)$ & $915.0(592.5 ; 1272)$ & $<0.001$ & 0.14 \\
\hline MDS-UPDRS part I score, median [IQR] & $7.0(5.0 ; 9.0)$ & $15.5(11.5 ; 19.0)$ & $<0.001$ & $<0.001$ \\
\hline MDS-UPDRS part II score, median [IQR] & $5.0(3.0 ; 6.0)$ & $11.0(7.0 ; 15.5)$ & $<0.001$ & 0.004 \\
\hline MDS-UPDRS part III score, median [IQR] & $25.0(18.0 ; 34.0)$ & $43.0(35.5 ; 50.5)$ & $<0.001$ & $0.004 * *$ \\
\hline MDS-UPDRS part IV score, median [IQR] & $7.0(6.0 ; 9.0)$ & $11.0(7.0 ; 13.0)$ & $<0.001$ & 0.004 \\
\hline
\end{tabular}




\begin{tabular}{l} 
Patients with motor fluctuations, $\mathbf{n}(\%)$ \\
\hline Hoehn \& Yahr grade, median [IQR] \\
\hline MoCA score, median [IQR] \\
\hline HAD anxiety, median [IQR] \\
\hline HAD depression, median [IQR] \\
\hline PDQ8 score, median [IQR] \\
Physiotherapy, $\mathbf{n}(\%)$ \\
Number of physiotherapy sessions per week, median [IQR]
\end{tabular}

\begin{tabular}{c}
\hline $47(50.5)$ \\
\hline $2.0(2.0 ; 2.0)$ \\
\hline $27.0(26.0 ; 29.0)$ \\
\hline $4.0(3.0 ; 6.0)$ \\
\hline $3.0(2.0 ; 5.0)$ \\
\hline $6.0(4.0 ; 9.0)$ \\
\hline $41(44.1)$ \\
\hline $3.0(2.0 ; 3.0)$ \\
\hline $5(5.4)$
\end{tabular}

\begin{tabular}{c}
\hline $53(88.3)$ \\
\hline $2.5(2.5 ; 3.0)$ \\
\hline $25.0(23.0 ; 26.0)$ \\
\hline $11.0(8.0 ; 13.0)$ \\
\hline $8.5(6.0 ; 11.00)$ \\
\hline $16.0(12.0 ; 19.0)$ \\
\hline $44(73.3)$ \\
\hline $3.0(2.0 ; 3.0)$ \\
\hline $18(30.0)$
\end{tabular}

\begin{tabular}{cc}
\hline$<0.001$ & 0.69 \\
\hline$<0.001$ & $0.007^{* * *}$ \\
\hline$<0.001$ & 0.11 \\
\hline$<0.001$ & $<0.001$ \\
\hline$<0.001$ & 0.0005 \\
\hline$<0.001$ & $<0.001$ \\
\hline$<0.001$ & 0.79 \\
\hline 0.040 & 0.26 \\
\hline$<0.001$ & 0.62
\end{tabular}

PI/GD: postural instability/gait disorder; DBS: deep brain stimulation; STN: subthalamic nucleus; MDS-UPDRS: Movement disorders society-Unified Parkinson's disease rating scale. NA: not applicable because population<8. MoCA: Montréal Cognitive Assessment; HAD: Hospital Anxiety and Depression scale; PDQ: Parkinson's disease questionnaire.

*adjusted for MDS-UPDRS part III score and Hoehn \& Yahr grade

** adjusted for Hoehn and Yahr grade

***adjusted for MDS-UPDRS part III score 


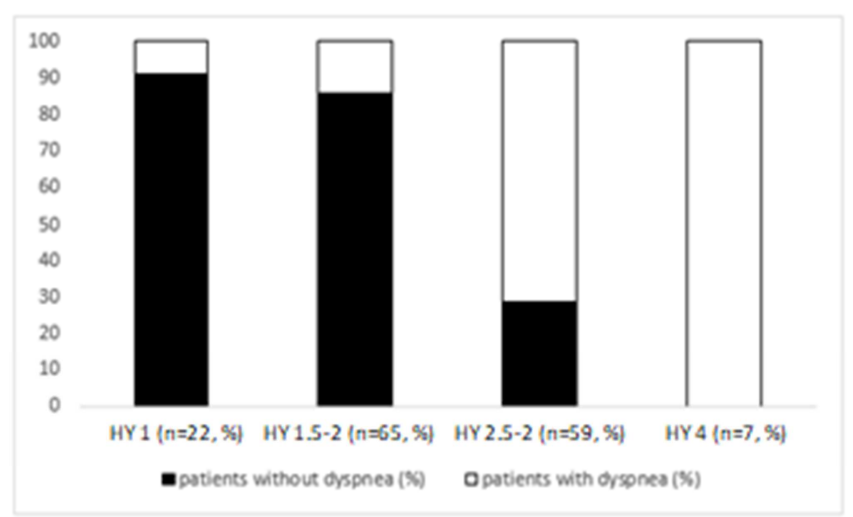

Figure 1A: the prevalence of dyspnea as a function of the H\&Y stage ( $p<0.001$ in a Cochran-Armitage test).

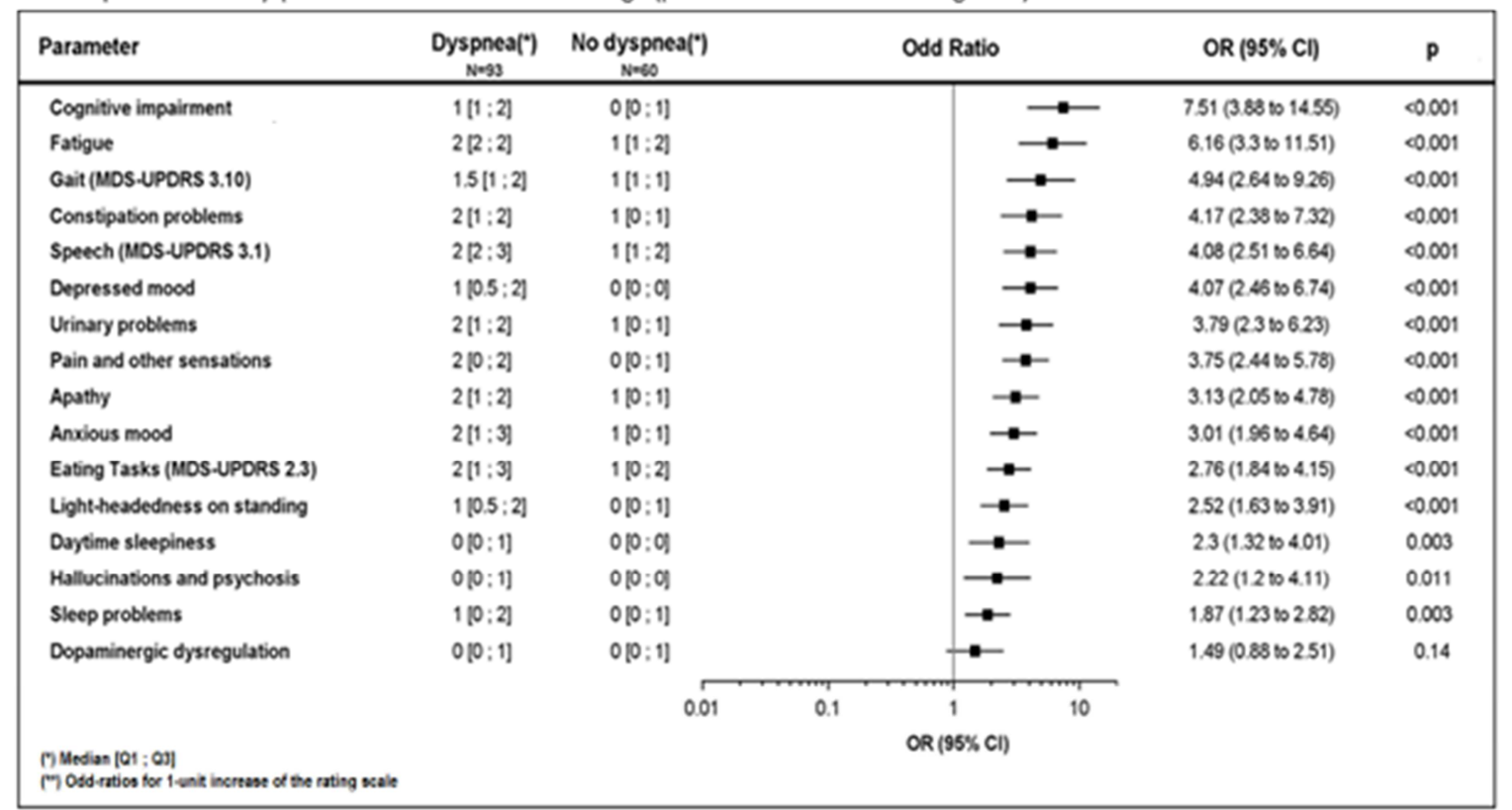

Figure 18: Forest-plot representing associations between dyspnea and the nonmotor aspects of problems in activities of daily living. MDS-UPDRS: Movement Disorders Society-Unified Parkinson's Disease Rating Scale. The results were not adjusted for disease motor severity. 
Highlights:

- Dyspnea is a frequent symptom in Parkinson's disease

- It is related to disease severity.

- It is linked to non-motor aspects of Parkinson's disease notably to anxiety and depression. 